1 Accepted for publication in Applied Microbiology and Biotechnology -

2 doi: $10.1007 / \mathrm{s} 00253-011-3590-\mathrm{y}$

\title{
Dynamic changes in the microbial community composition in microbial fuel cells fed with sucrose
}

\section{Nelli J. Beecroft ${ }^{1}$, Feng Zhao ${ }^{3, a}$, John R. Varcoe ${ }^{3}$, Robert C.T. Slade ${ }^{3}$, Alfred E. Thumser ${ }^{2}$, Claudio Avignone-Rossa ${ }^{1 *}$}

\author{
*Corresponding Author \\ Claudio Avignone-Rossa \\ Mailing address: Faculty of Health and Medical Sciences, \\ University of Surrey, Guildford, GU2 7XH, UK \\ Phone: +44 (0) 1483686457 \\ Fax: +44 (0) 1483686401 \\ E-mail: c.avignone-rossa@surrey.ac.uk
}


Use of a second DGGE for re-amplified 16S rRNA genes of bands from the first DGGE to yield sequences of better quality. Co-migration of DNA molecules of different sequence to the

47 same position in a denaturing gradient is a limiting factor in the analysis of complex microbial

48 communities by DGGE (Gafan and Spratt 2005; Kowalchuk et al. 1997; Satokari et al. 2001;

49 Green et al. 2009), and was also observed in the study described here. The 16S rRNA genes of

50 bands marked with -'- in the DGGE of bacterial community profiles (Fig. S3) were re-amplified

51 by PCR and run on a second DGGE gel with a narrower denaturing gradient because of

52 insufficient quality of sequences (partly overlapping sequences in a chromatogram) obtained

53 from the first DGGEs possibly due to co-migration of several sequences in one band. The second

54 DGGE round (Fig. S3) showed one main band in each sample yielding sequencing results of 55 good quality.

Dynamics of bacterial classes. MFCs B and C showed increasing abundances of Clostridia and

58 decreasing abundances of Bacteroidetes (Fig. S6 b and c). An increase in the relative proportion

59 of $\delta$-Proteobacteria and $\beta$-Proteobacteria could be seen in MFC-A and MFC-B, respectively

60 (Fig. S6 a and b). At the end of MFC operation, Clostridia was the most abundant class in the

61 anodic biofilm of all MFCs $((41 \pm 5.6) \%, \mathrm{n}=3)$, followed by $\delta$-Proteobacteria $(20 \%)$ and

62 Bacteroidetes (15\%) in MFC-A, Bacteroidetes (33\%) and $\beta$-Proteobacteria (16\%) in MFC-B

63 and Bacteroidetes (18\%) and $\gamma$-Proteobacteria (16\%) in MFC-C (Fig. S6 a-c).

64 Decreasing abundances of Bacteroidetes were observed both in the anodic suspensions of 65 MFC-B and MFC-C over time (Fig. S6 e and f). At the end of MFC operation, Clostridia was the 66 most abundant class also in the anodic suspension of all MFCs $((46 \pm 3.9) \%, n=3)$, followed by 
$67 \delta$ - (11\%) and E-Proteobacteria (10\%) in MFC-A, $\beta$-Proteobacteria $(20 \%)$ and Bacilli $(20 \%)$ in

68 MFC-B and $\varepsilon-(33 \%)$ and $\beta$-Proteobacteria (8\%) in MFC-C (Fig. S6 d-f).

70 Control MFC. A control MFC was operated in open circuit, simultaneously with an MFC

71 connected to an external resistor. Other operational conditions used for these two MFCs were as

72 described for MFCs A-C, with the exception that the loading rate was $0.05 \mathrm{ml} \mathrm{min}^{-1}$ and the

73 sucrose concentration of the feed was $0.17 \mathrm{~g} \mathrm{~L}^{-1}$. The anodic bacterial community was sampled

74 for PCR-DGGE analysis on day 66.

75 Most species detected according to their 16S rRNA sequence in the current-producing MFC 76 were also found in MFCs A-C (Fig. S7). Some species (bands 3-5) were members of the anodic 77 biofilm community both in the current-producing and the control MFC (Table S1). Notably, the 78 species related to Rhodocyclus sp. HOD 5 (100\% similarity), Robinsoniella peoriensis strain 79 PPC31 (99\%) and Anaerosporobacter mobilis strain IMSNU 40011 (100\%) were detected only 80 in the current-producing MFC. However, since the presence or the relative proportions of these 81 bacteria were not temporarily consistent in the replicate MFCs, it is not possible to deduce that 82 any specific species would be the main current-producers in the anodic communities.

\section{Archaeal community analysis}

85 Results. Archaea can contribute to the organic removal in MFCs fed with fermentable 86 substrates, but also cause a loss of electrons through the production of $\mathrm{CH}_{4}$. The dynamics of the 87 archeal communities in the MFCs was subjected to study by PCR-DGGE, followed by species 88 identification by sequencing. The DGGE patterns of the archaeal communities of anodic biofilm 89 and suspension were very similar and most species were already detected in the inoculum (day 0) 
90 (Fig. S8). A small number of different species $(1-3)$ were dominant at any time point and no

91 significant change in communities over time was observed, with the exception of MFC-C (Fig.

92 S8 and S9). An archaeon with sequence similarity to Methanosaeta concilii (98-99\%) was the

93 main species found in all MFCs (bands 1, 2 and 4) (Fig. S8 and S9). In MFC-C, sequences

94 closely related to Methanosarcina barkeri (99\%) were detected at the end of operation (days 70

95 and 91) in both the biofilm (band 3) and suspension (band 5). In addition, a species with 98\%

96 sequence similarity to the uncultured archaeon clone W30D and distantly related to

97 Thermoplasma volcanium (81\%) was a member of the suspended microbial community in MFC-

98 C (days 56-91).

99

Discussion. Archaeal communities showed much less diversity than the bacterial 101 communities. Methanosaeta concilii was the dominant archaeal species in the anodic biofilm and 102 suspension of all replicate MFCs, with the exception of Methanosarcina barkeri and an 103 uncultured archaeon clone detected in MFC-C at the end of operation (Fig. S8 and Fig. S9). M.

104 concilii is an acetate-fermenter whereas $M$. barkeri grows either on acetate or hydrogen (Garcia 105 et al. 2006). Thus, in these sucrose-fed MFCs, methanogenic archaea would compete with 106 exoelectrogenic bacteria mainly for acetate, as shown in acetate-fed MFCs (Virdis et al. 2009).

107 In studies with glucose, ethanol or cellulose as substrate, $\mathrm{H}_{2}$-oxidizing methanogens were found 108 to compete or even out-compete the $\mathrm{H}_{2}$-utilizing exoelectrogens, whereas acetoclastic 109 methanogenesis was not detected (Freguia et al. 2008; Ishii et al. 2008; Parameswaran et al. 110 2009). Acetoclastic and hydrogenotrophic methanogens accounted for around $19 \%$ and 5\%, 111 respectively, of the total microbial community in a glucose-fed MFC (Chung and Okabe 2009). 112 Both acetoclastic (Methanosaeta sp.) and hydrogenotrophic (Methanobacterium sp. and 
113 Methanospirillum sp.) methanogens were also members of anodic biofilm community in a

114 glucose- and lactate-fed MFC (Borole et al. 2009). The presence of acetoclastic methanogens in

115 the sucrose-fed MFCs of this study represents a loss of electrons to methane, giving rise to a

116 need of suppressing these methanogens e.g. by periodic aeration in order to promote the growth

117 of acetate-oxidizing exoelectrogens (e.g. facultative denitrifiers would not be suppressed by

118 aeration) and to improve the current output of MFCs.

\section{$121 \quad$ References}

122

123

124

125

126

127

128

129

130

131

132

133

134

Borole AP, Hamilton CY, Vishnivetskaya TA, Leak D, Andras C, Morrell-Falvey J, Keller M, Davison B (2009) Integrating engineering design improvements with exoelectrogen enrichment process to increase power output from microbial fuel cells. J Power Sour 191:520-527

Chung K, Okabe S (2009) Continuous power generation and microbial community structure of the anode biofilms in a three-stage microbial fuel cell system. Appl Microbiol Biotechnol 83:965-977

Freguia S, Rabaey K, Yuan Z, Keller J (2008) Syntrophic processes drive the conversion of glucose in microbial fuel cell anodes. Environ Sci Technol 42:7937-7943

Gafan GP, Spratt DA (2005) Denaturing gradient gel electrophoresis gel expansion (DGGEGE) an attempt to resolve the limitations of co-migration in the DGGE of complex polymicrobial communities. FEMS Microbiol Lett 253:303-307

Garcia J-L, Ollivier B, Whitman WB (2006) The Order Methanomicrobiales. The Prokaryotes. Springer Science, New York, USA, pp 208-230

Green SJ, Leigh MB, Neufeld JD (2009) Denaturing gradient gel electrophoresis (DGGE) for microbial community analysis. In: Timmis KN (ed) Microbiology of hydrocarbons, oils, lipids and derived compounds. Heidelberg, Germany, pp 4137-4158

Ishii S, Shimoyama T, Hotta Y, Watanabe K (2008) Characterization of a filamentous biofilm community established in a cellulose-fed microbial fuel cell. BMC Microbiol 8:6

Kowalchuk GA, Stephen JR, de Boer W, Prosser JI, Embley TM, Woldendorp JW (1997) Analysis of ammonia-oxidizing bacteria of the beta subdivision of the class Proteobacteria in coastal sand dunes by denaturing gradient gel electrophoresis and 
144

146

147

148

149

150

151

152

153

154

155

156

157

158

159

160

161

162

163

164

165

166

167

168

169

170

171

172

173

174

175

176

177

178

179

180

181

182

183

184

185

186

187 sequencing of PCR-amplified 16S ribosomal DNA fragments. Appl Environ Microbiol 63:1489-1497

Parameswaran P, Torres CI, Lee H-S, Krajmalnik-Brown R, Rittmann BE (2009) Syntrophic interactions among anode respiring bacteria (ARB) and non-ARB in a biofilm anode: electron balances. Biotechnol Bioeng 103:513-523

Satokari RM, Vaughan EE, Akkermans ADL, Saarela M, de Vos WM (2001) Bifidobacterial diversity in human feces detected by genus-specific PCR and denaturing gradient gel electrophoresis. Appl Environ Microbiol 67:504-513

Virdis B, Rabaey K, Yuan Z, Rozendal RA, Keller J (2009) Electron fluxes in a microbial fuel cell performing carbon and nitrogen removal. Environ Sci Technol 43:5144-5149 
Figure S1. An exemplar polarization curve (•) and power density curve ( $\boldsymbol{\square})$ of MFC-D on day 91.

Figure S2. DNA concentrations in (a) anodic biofilm and (b) suspension of MFC-A ( $)$, MFC-B

Figure S3. DGGE of re-amplified 16S rRNA genes of bands marked with -'- in the DGGE of bacterial community profiles of MFCs A-C, with denaturing gradients ranging from (a) 40 to

$19755 \%$ and (b) 40 to $60 \%$.

Figure S4. Proportion trends of the most abundant species in the anodic biofilm of MFC-A and MFC-B based on band intensities of DGGE community profiles and identification of excised bands by sequencing and comparison to known 16S rRNA sequences in Genbank.

Figure S5. Proportion trends of the most abundant species in the anodic suspension of MFC-A and MFC-B based on band intensities of DGGE community profiles and identification of excised 205 bands by sequencing.

Figure S6. Relative abundances of bacterial classes in the anodic biofilm of MFCs A (a), B (b) 208 and C (c) and in the suspended culture of MFCs A (d), B (e) and C (f): $\alpha-(\boldsymbol{\bullet}), \beta-(\boldsymbol{\square}), \gamma-(\boldsymbol{\Delta}), \delta-$ $209(\nabla)$ and E-Proteobacteria $(\diamond) ;$ Clostridia (O), Bacteroidetes $(\square)$, Spirochaetes $(\triangle)$, 210 Actinobacteria $(\nabla)$, Flavobacteria $(\diamond)$, Bacilli $(*)$, and unknown $(\diamond)$. 
212 Figure S7. DGGE profile of anodic bacterial communities of an MFC connected to external

213 resistor (left) and a contol MFC operated in open circuit (right) analyzed by DGGE of PCR-

214 amplified genes coding for 16S rRNA. Numbers indicate bands identified by sequence analysis.

216 Figure S8. DGGE profile of archaeal communities of the anodic biofilm (a) and suspended

217 culture (b) analyzed by DGGE of PCR-amplified genes coding for 16S rRNA; Std: Standard

218 mix; Inoc: anaerobic sludge. Arrows indicate bands excised for sequence analysis. Same

219 numbering is used for identical sequences.

220

221 Figure S9. Phylogenetic tree based on partial archaeal 16S rRNA gene sequences of anodic 222 biofilm and suspended culture of three replicate sucrose-fed MFCs. Sequences found only in 223 biofilm or suspension are marked with ' $\mathrm{b}$ ' or ' $\mathrm{s}$ ', respectively. The tree was constructed using 224 distance matrix and neighbour joining algorithm with 1,000 bootstrappings. The bootstrap values $225 \leq 99 \%$ are shown. A bacterium Clostridium indolis (Y18184) was used as out-group. The scale 226 bar represents $10 \%$ sequence divergence. 
230 Table S1. Bacterial 16S rRNA gene sequences of bands exsiced from the DGGE gel of anodic

231 biofilm bacteria in a control (open-circuit) and electricity-producing MFCs.

\begin{tabular}{|c|c|c|c|c|c|}
\hline Band & MFC & $\begin{array}{l}\text { Accession } \\
\text { no. }\end{array}$ & GenBank match (accession no.) & $\begin{array}{l}\text { Simil. } \\
(\%)\end{array}$ & Class \\
\hline 1 & $\begin{array}{l}\text { Current- } \\
\text { producing }\end{array}$ & JF330839 & $\begin{array}{llr}\text { Anaerosporobacter mobilis } & \text { strain } \\
\text { IMSNU 40011 (AY534872) } & \end{array}$ & 100 & Clostridia \\
\hline 2 & $\begin{array}{l}\text { Current- } \\
\text { producing }\end{array}$ & JF330840 & $\begin{array}{l}\text { Robinsoniella peoriensis strain PPC31 } \\
\text { (AF445285) }\end{array}$ & 99 & Clostridia \\
\hline 3 & $\begin{array}{l}\text { Control/Current- } \\
\text { producing }\end{array}$ & JF330841 & $\begin{array}{l}\text { Clostridium indolis strain DSM } 755 \\
\text { (Y18184) }\end{array}$ & 99 & Clostridia \\
\hline 4 & $\begin{array}{l}\text { Control/Current- } \\
\text { producing }\end{array}$ & JF330842 & $\begin{array}{llll}\begin{array}{l}\text { Ochrobactrum anthropi } \\
\text { (EU275247) }\end{array} & \text { strain } & \text { YZ-1 } \\
\end{array}$ & 100 & $\alpha$-Proteobacteria \\
\hline 5 & $\begin{array}{l}\text { Current- } \\
\text { producing }\end{array}$ & JF330843 & Rhodocyclus sp. HOD 5 (AY691423) & 100 & $\beta$-Proteobacteria \\
\hline 6 & $\begin{array}{l}\text { Control/Current- } \\
\text { producing }\end{array}$ & JF330844 & $\begin{array}{l}\begin{array}{l}\text { Petrimonas sulfuriphila } \\
\text { (AY570690) }\end{array} \\
\text { strain }\end{array}$ & 97 & Bacteroidetes \\
\hline 7 & Control & JF330845 & $\begin{array}{l}\text { Ochrobactrum anthropi strain CCUG } \\
50899 \text { (AM490609) }\end{array}$ & 100 & $\alpha$-Proteobacteria \\
\hline 8 & Control & JF330846 & $\begin{array}{llll}\begin{array}{l}\text { Luteibacter } \\
\text { (FM212561) }\end{array} & \text { sp. } & \text { CCUG } & 25036 \\
\end{array}$ & 99 & $\gamma$-Proteobacteria \\
\hline 9 & Control & JF330847 & Gordonia sp. IFM 10067 (AB476396) & 99 & Actinobacteria \\
\hline
\end{tabular}


Figure S1.

236

237

238

239

240

241

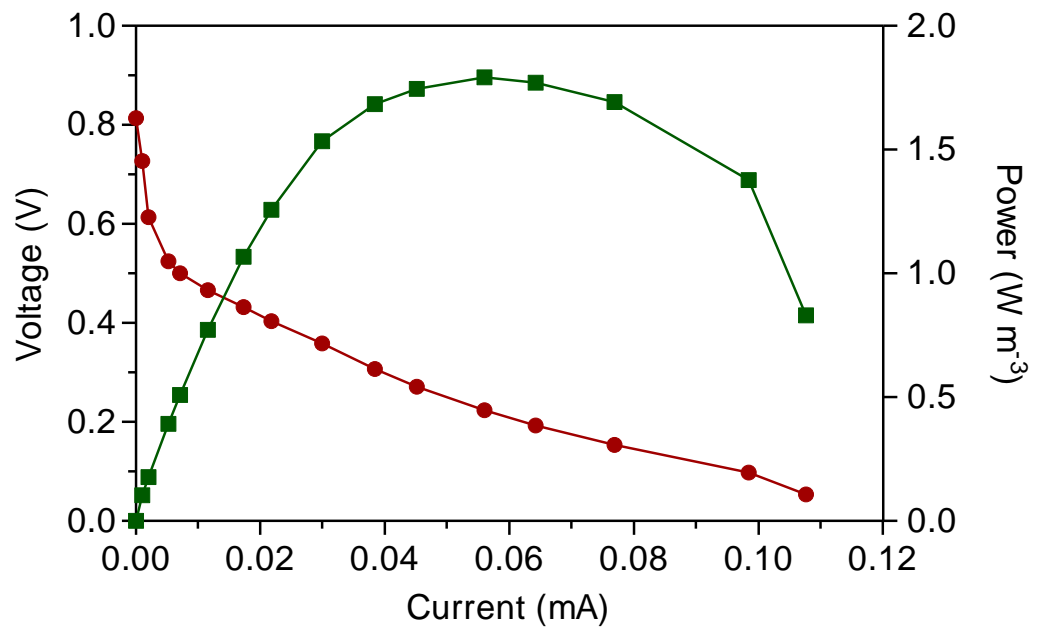


Figure S2.

251
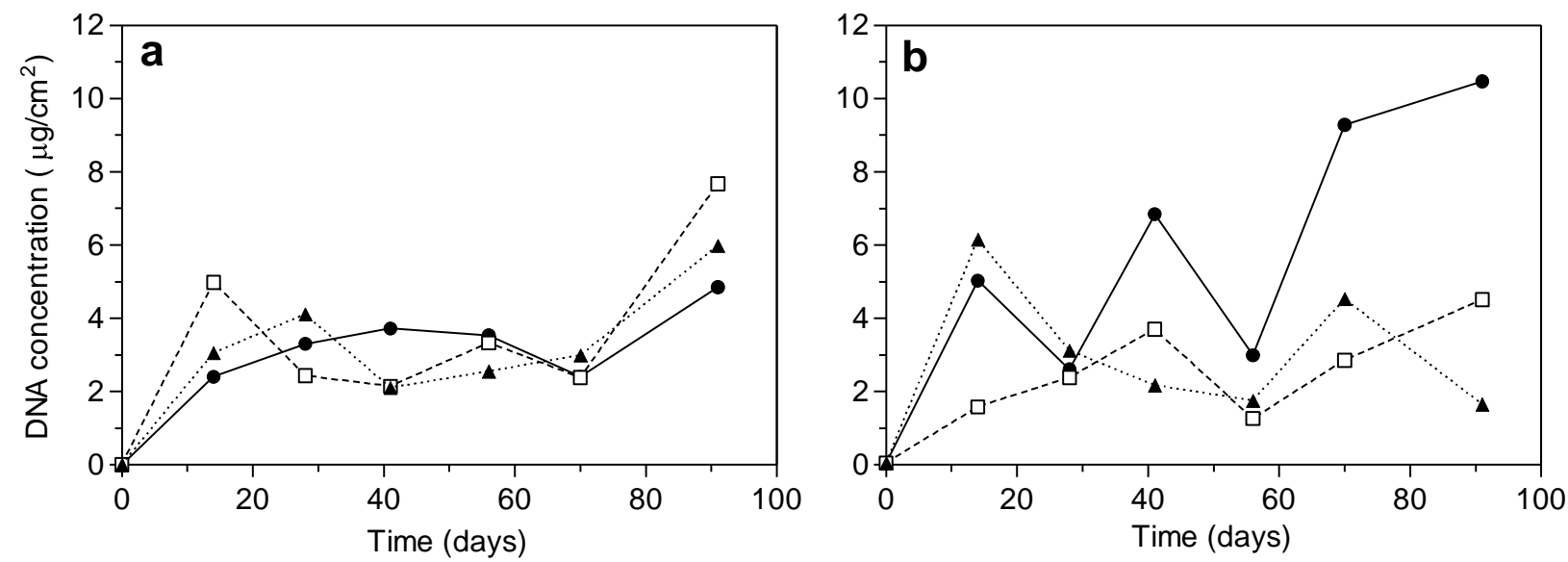
$256 \quad$ Figure S3.

257

258

259

260

261

262

263

264

265

266

267

268

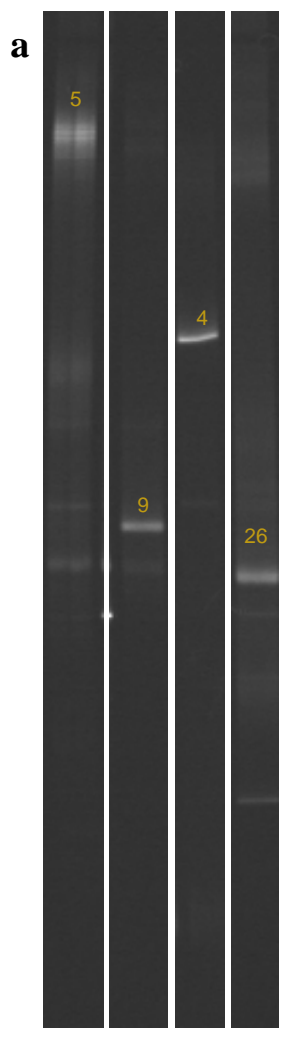

b

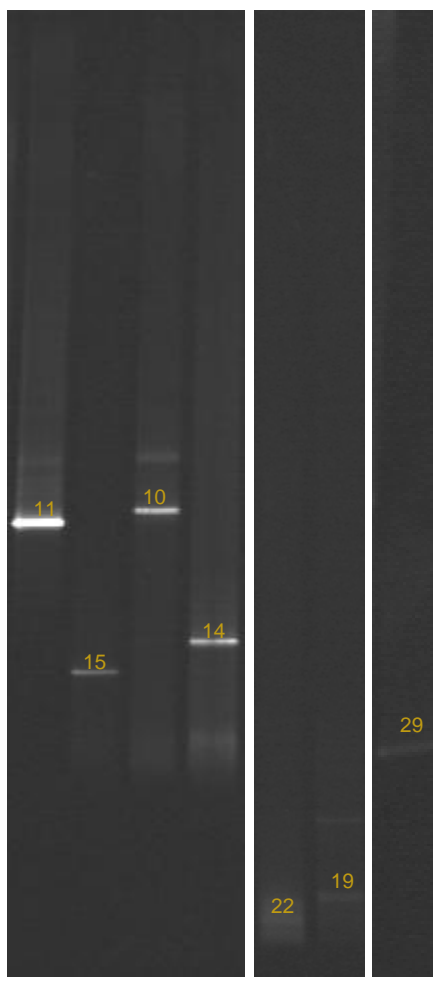

269

270 
$273 \quad$ Figure S4.

274

275
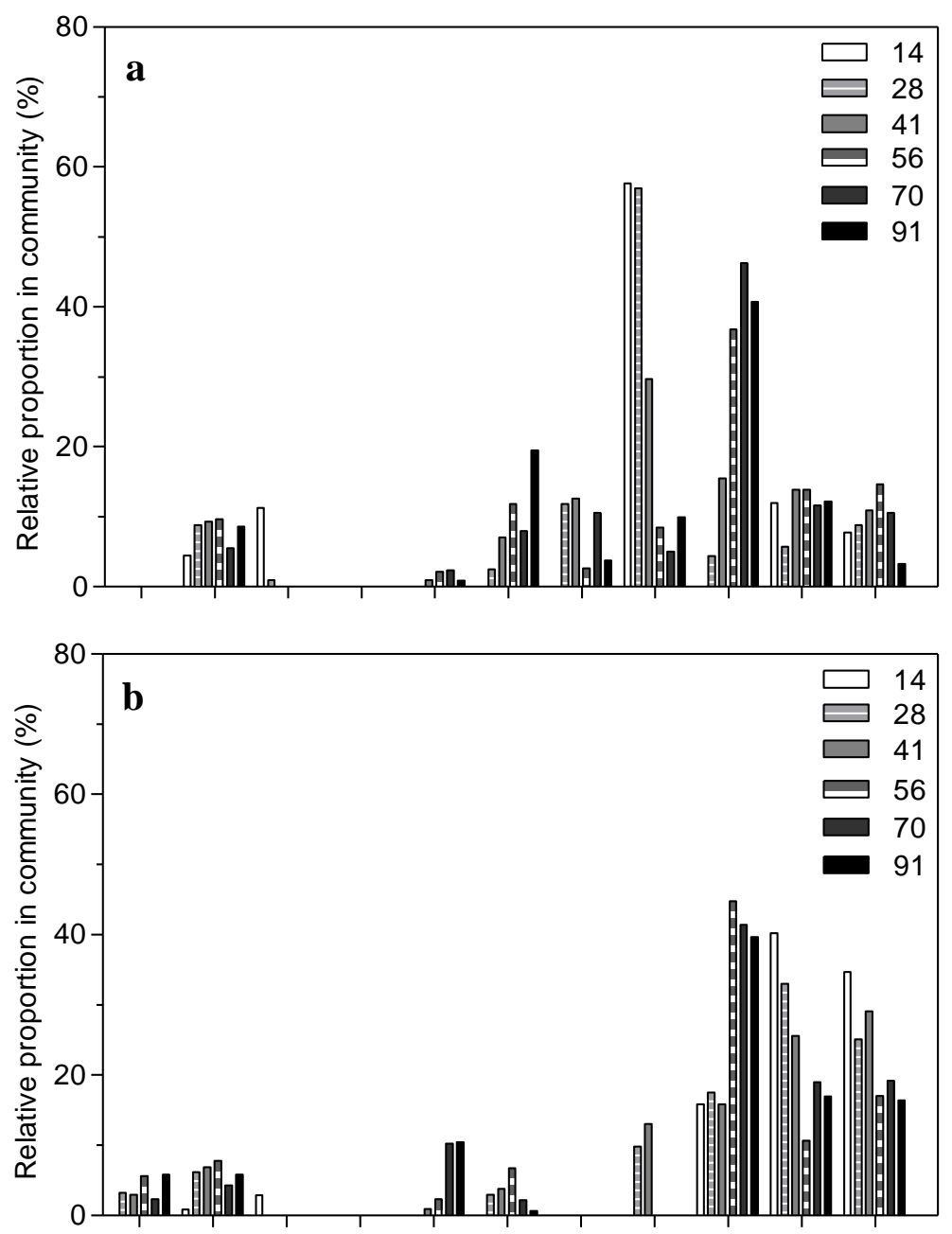

276

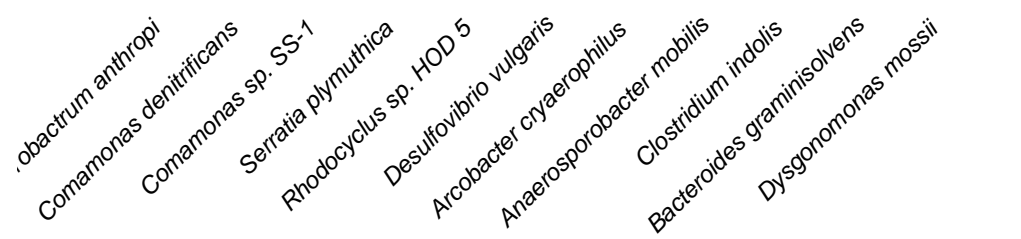


Figure S5.
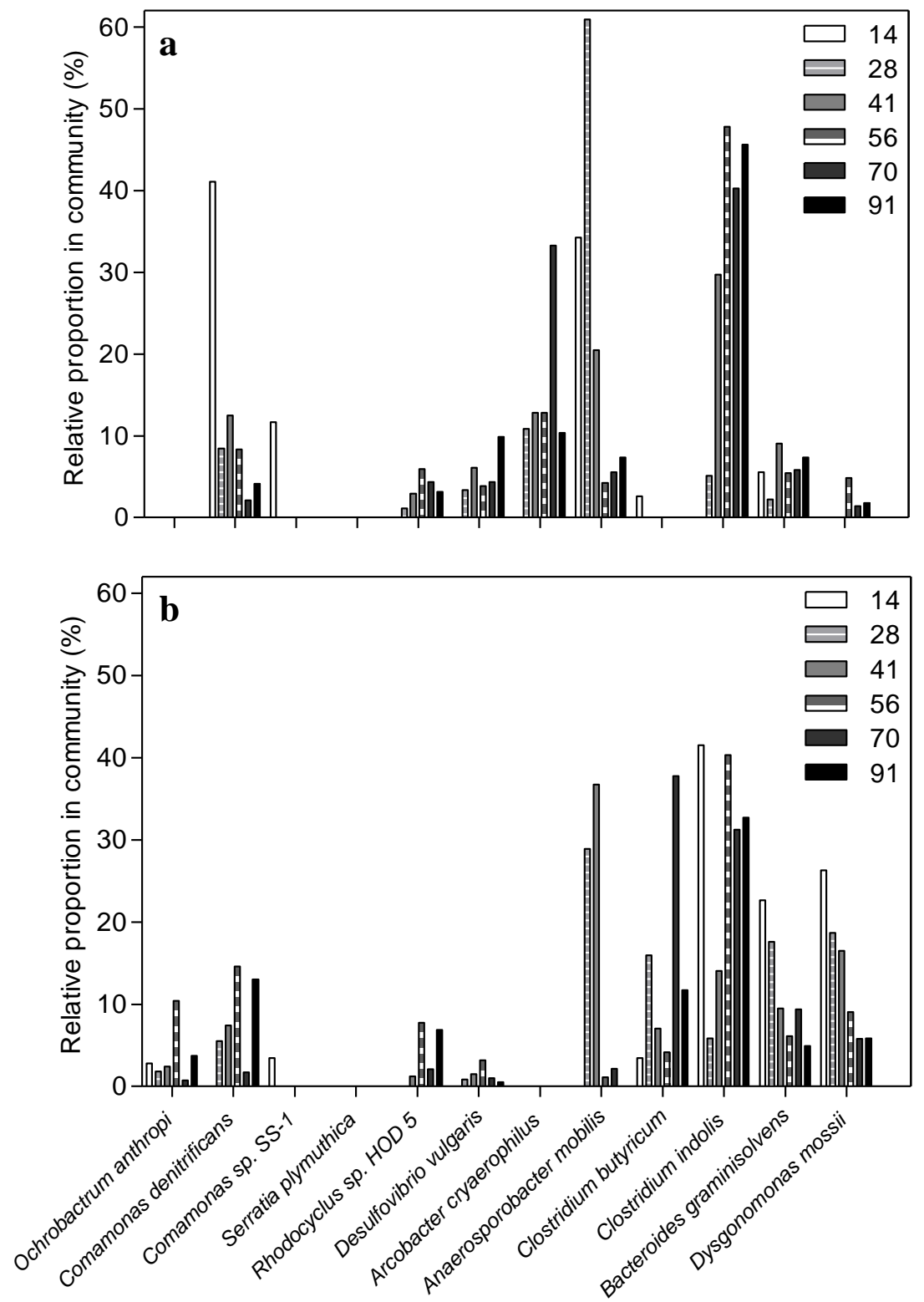
Figure S6.
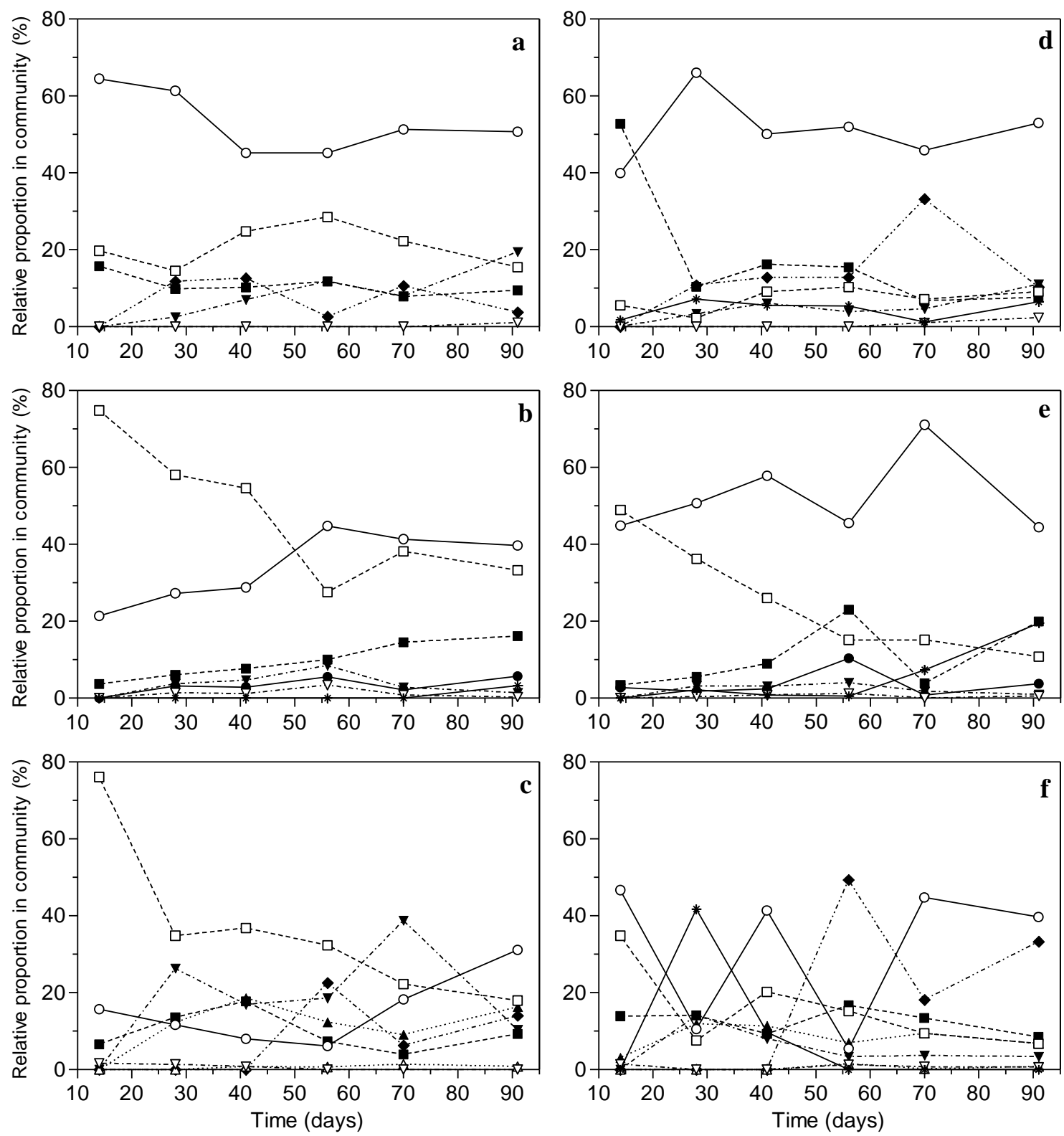
$287 \quad$ Figure S7.

288

289

290

291

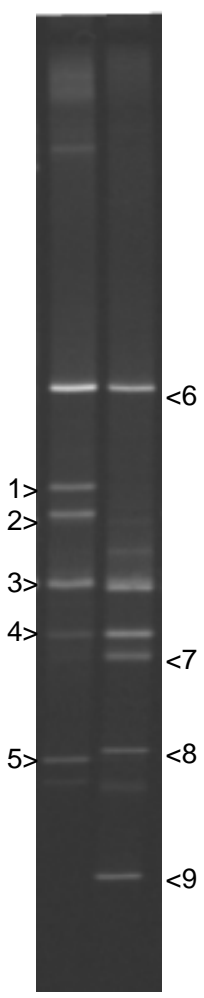

292 
Microbial community dynamics in MFCs

\section{$293 \quad$ Figure S8.}

294

295

a

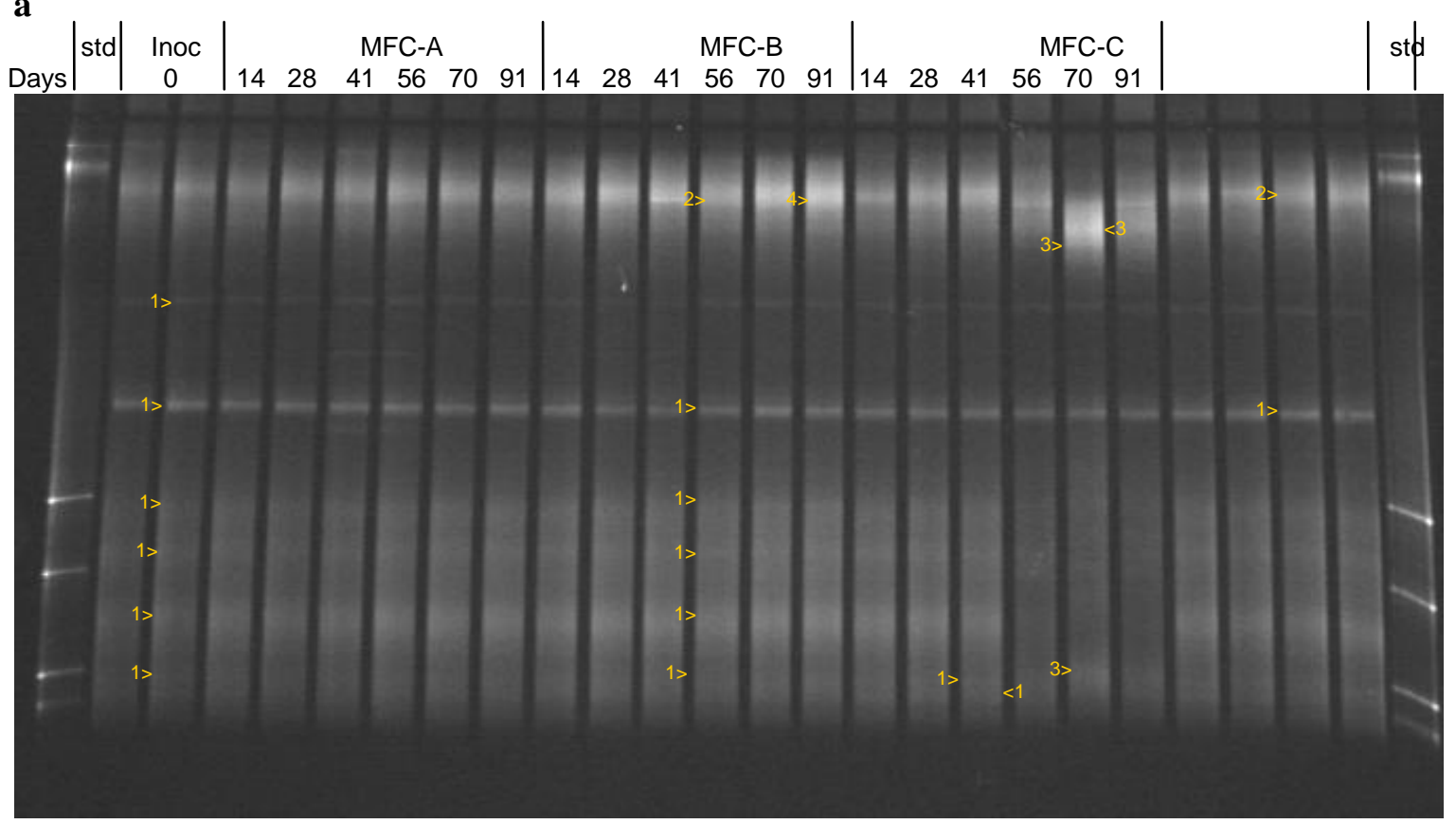

296

b

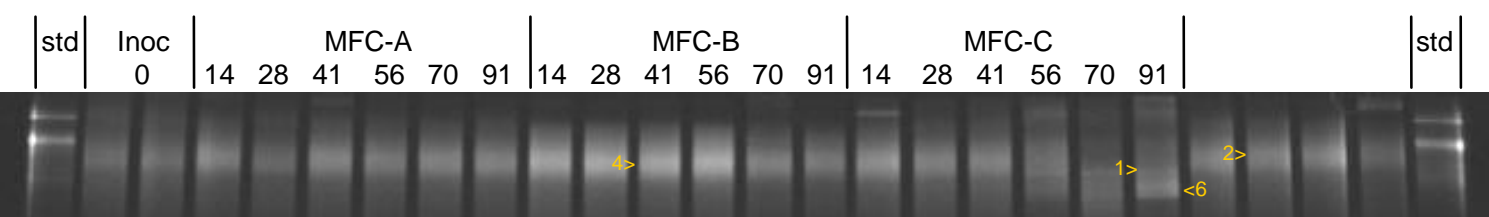




\section{$299 \quad$ Figure S9.}

300

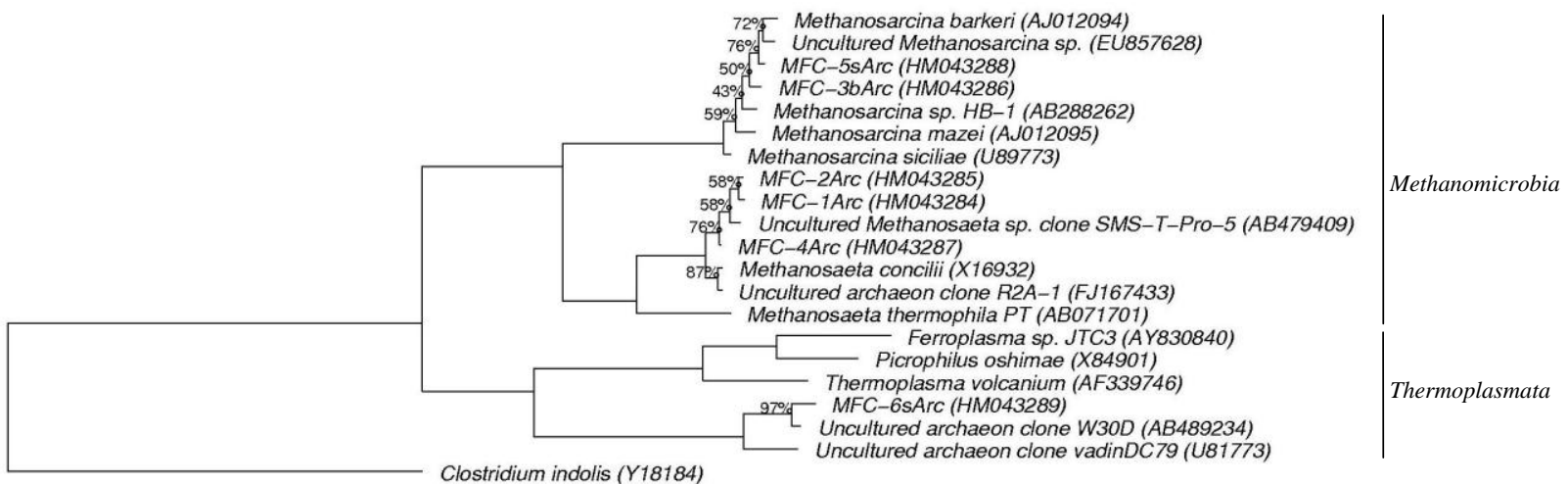

301

0.10

302

303

304 